\title{
Comparison of the second and third intercostal spaces regarding the use of internal mammary vessels as recipient vessels in DIEP flap breast reconstruction: An anatomical and clinical study
}

\author{
Ik Hyun Seong, Kyong-Je Woo \\ Department of Plastic and Reconstructive Surgery, Ewha Womans University Mokdong Hospital, College of Medicine, Ewha Womans University, \\ Seoul, Korea
}

Background The purpose of this study was to compare the anatomical features of the internal mammary vessels (IMVs) at the second and third intercostal spaces (ICSs) with regard to their use as recipient vessels in deep inferior epigastric artery perforator (DIEP) flap breast reconstruction.

Methods A total of 38 consecutive DIEP breast reconstructions in 36 patients were performed using IMVs as recipient vessels between March 2017 and August 2018. The intraoperative findings and postoperative complications were analyzed. Anatomical analyses were performed using intraoperative measurements and computed tomography (CT) angiographic images.

Results $\mathrm{CT}$ angiographic analysis revealed the mean diameter of the deep inferior epigastric artery to be $2.42 \pm 0.27 \mathrm{~mm}$, while that of the deep inferior epigastric vein was $2.91 \pm 0.30$ $\mathrm{mm}$. A larger mean vessel diameter was observed at the second than at the third ICS for both the internal mammary artery $(2.26 \pm 0.32 \mathrm{~mm}$ vs. $1.99 \pm 0.33 \mathrm{~mm}$, respectively; $P=0.001)$ and the internal mammary vein (IMv) $(2.52 \pm 0.46 \mathrm{~mm}$ vs. $2.05 \pm 0.42 \mathrm{~mm}$, respectively; $P<0.001)$. Similarly, the second ICS was wider than the third $(18.08 \pm 3.72 \mathrm{~mm}$ vs. $12.32 \pm 2.96 \mathrm{~mm}$, respectively; $P<0.001)$ and the distance from the medial sternal border to the medial IMv was greater $(9.49 \pm 2.28 \mathrm{~mm}$ vs. $7.18 \pm 2.13 \mathrm{~mm}$, respectively; $\mathrm{P}<0.001)$. Bifurcations of the $\mathrm{IMv}$ were found in $18.4 \%$ of cases at the second ICS and in $63.2 \%$ of cases at the third ICS.

Conclusions The IMVs at the second ICS had more favorable anatomic features for use as recipient vessels in DIEP flap breast reconstruction than those at the third ICS.

Keywords Anatomy / Breast neoplasms / Breast reconstruction / Internal mammary arteries
Correspondence: Kyong-Je Woo Department of Plastic and

Reconstructive Surgery, Ewha Womans University Mokdong Hospital, College of Medicine, Ewha Womans University, 1071 Anyangcheon-ro, Yangcheon-gu, Seoul 07985, Korea

Tel: +82-2-2650-5149

Fax: +82-2-2650-5278

E-mail:economywoo@gmail.com

Received: September 20, $2019 \bullet$ Revised: April 12, $2020 \bullet$ Accepted: May 25, 2020

pISSN: 2234-6163 • elSSN: 2234-6171 • https://doi.org/10.5999/aps.2019.01312 • Arch Plast Surg 2020;47:333-339

\section{INTRODUCTION}

Breast reconstruction surgery is becoming increasingly common [1]. The gold standard among breast reconstruction meth- ods that utilize autologous tissue is deep inferior epigastric artery perforator (DIEP) flap reconstruction. While the thoracodorsal artery can be a recipient vessel for DIEP flap reconstruction, the internal mammary artery (IMA) has become the

Copyright $(\odot) 2020$ The Korean Society of Plastic and Reconstructive Surgeons

This is an Open Access article distributed under the terms of the Creative Commons Attribution Non-Commercial License (https://creativecommons.org/

licenses/by-nc/4.0/) which permits unrestricted non-commercial use, distribution, and reproduction in any medium, provided the original work is properly cited.

www.e-aps.org 
most common recipient vessel. IMA perforators are also potential recipient vessels, and their superficial location results in better accessibility and allows dissection to be performed less invasively. However, the use of IMA perforators has not yet become standard and has only been described in a handful of studies with small sample sizes [2].

The use of the IMA and its perforators as recipient vessels has the following advantages. First, relative to the branches of the thoracodorsal axis, the caliber of the internal mammary vessels (IMVs) matches well with that of the deep inferior epigastric vessels. Second, IMVs are typically not involved in oncological breast surgery, and they are more easily accessed for microsurgery than the thoracodorsal branches [3]. Third, the inset of the flap to create a natural breast shape is easier to perform when using IMVs due to their medial location relative to thoracodorsal vessels. However, a disadvantage of the use of IMVs is that exposure of these vessels requires the excision of a section of costal cartilage, which may cause a contour defect in the medial area of the breast [4]. Additionally, the use of the IMA as a recipient vessel in breast reconstruction means that the vessel cannot be utilized subsequently for cardiac bypass [5].

In recent years, when IMVs were used as recipient vessels, a rib-sparing method was attempted to reduce morbidity. However, the partial or total resection of rib cartilage is necessary when the intercostal space (ICS) is too narrow for microvascular anastomosis to be performed. Exposure and dissection at either the second or the third ICS can be used for recipient vessel preparation in DIEP breast reconstruction. However, it has not been clearly elucidated whether the use of the second or third ICS is better for recipient vessel preparation in such reconstructions.

The purpose of this study was to investigate the anatomical and clinical characteristics of the second and third ICS in order to determine which is superior for recipient vessel dissection in DIEP flap reconstruction. This study focused in particular on the relative diameters of the second and third IMVs and the donor vessels of the DIEP flap.

\section{METHODS}

Retrospective analysis was performed of 38 DIEP flap breast reconstructions in 36 consecutive patients who underwent DIEP flap breast reconstruction at the investigators' hospital between March 2017 and August 2018. The study was approved by the institutional review board of the authors' institution (IRB No. 2020-04-013) and was performed in accordance with the principles of the Declaration of Helsinki. Written informed consent was obtained from the patients.

When planning a DIEP flap reconstruction, preoperative computed tomography (CT) angiography is performed to evaluate the donor and recipient sites and to obtain other information, thereby providing an effective guide to flap design and inset [6]. In the present study, all patients underwent preoperative CT angiography from $6 \mathrm{~cm}$ superior to the clavicle to the greater trochanter in a cranial to caudal direction to ensure that both the chest and abdomen were included. The INFINITT picture archiving and communication system (PACS; INFINITT Healthcare, Seoul, Korea) was used for measurements. Using preoperative CT angiography, the widths of the second and third ICS; the diameters of the IMA, internal mammary vein (IMv), deep inferior epigastric artery (DIEA), and deep inferior epigastric vein (DIEV); and the distance from the medial sternal border to the medial IMv were measured, and the presence of bifurcation of the IMv was assessed. IMv diameter was measured at the midpoint of the ICS. The diameters of the DIEA and the DIEV were measured approximately $1 \mathrm{~cm}$ above the origin to avoid sites of curvature of the vessels near their origin. In the INFINITT PACS (INFINITT Healthcare) program, the screen was magnified by a factor of 5.0, and values were measured using a two-dimensional ruler tool within the software (Fig. 1). Each variable was measured twice by each of two independent observers.

During surgery, the widths of the second and third ICS; the diameters of the IMA, IMv, DIEA, and DIEV; the distance from the medial sternal border to the medial IMv; and the presence of IMv bifurcation were evaluated directly in 11 patients (Fig. 2). The CT measurements and the intraoperative measurements were compared.

Statistical analysis was performed using SPSS software 18.0 (SPSS Inc., Chicago, IL, USA). All measurements were reported as means and standard deviations. Significance values were calculated using the independent t-test and the chi-square test. Pvalues $<0.05$ were considered to indicate statistical significance.

\section{RESULTS}

Among the 38 cases, immediate reconstructions were performed in $68.4 \%(26 / 38)$, while delayed reconstructions were performed in the remaining $31.6 \%$ (12/38). Turbocharged bipedicled flaps were used in $10.5 \%$ of cases $(4 / 38)$. The second ICS was chosen for recipient vessel dissection in 37 of the 38 cases; the only case in which the third ICS was chosen was one in which an inframammary incision had been used for the mastectomy. Total rib sparing using the second ICS was performed in $86.8 \%$ of cases $(33 / 38)$, while partial or total segments of the third rib cartilage were resected in the remaining five cases (13.2\%) (Table 1). End-to-end anastomosis was used for arteri- 


\section{Fig. 1. CT measurement of vessel diameter}

(A) The internal mammary artery (IMA) at the second intercostal space (ICS) was visible on the cross-sectional computed tomography (CT) angiography image in a patient for whom the left internal mammary vessels were used as recipient vessels. The green arrow points the left IMA. (B) Measurement of the diameter of the IMA using a 2-dimensional (2D) ruler tool at $\times 5$ magnification. The green arrow points the left IMA. (C) The contralateral pedicle of the deep inferior epigastric artery perforator was used. The deep inferior epigastric artery (DIEA) was clearly visible approximately $1 \mathrm{~cm}$ above the origin. The green arrow points the right DIEA. (D) The diameter of the DIEA was measured using the 2D ruler tool at $\times 5$ magnification. The green arrow points the right DIEA.
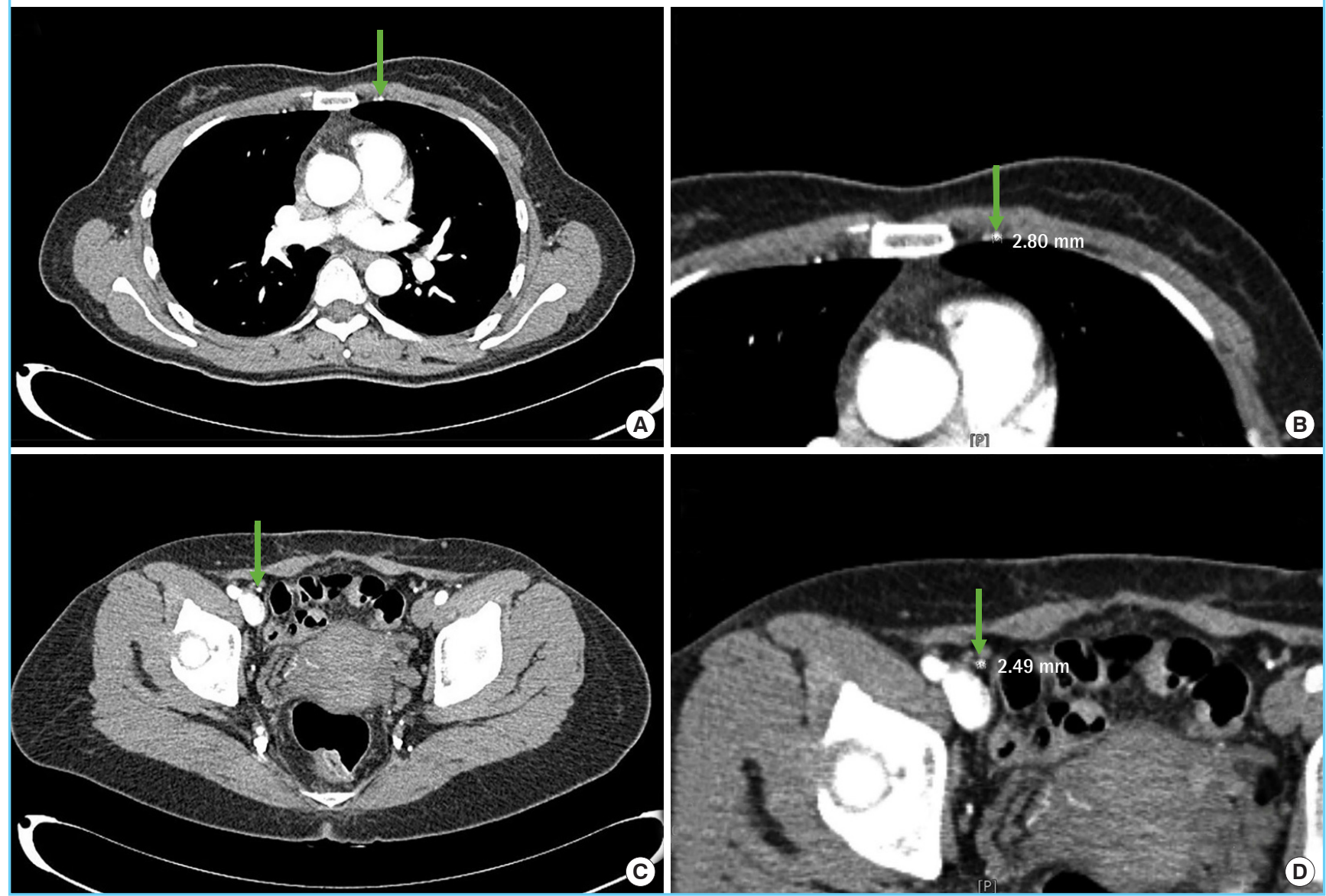

Fig. 2. Intraoperative measurement during DIEP breast reconstruction

(A) Direct intraoperative measurement of the diameter of the internal mammary vein using a ruler. (B) The second intercostal space was secured by retracting the skin flap using a skin hook and rubber band. DIEP, deep inferior epigastric artery perforator.
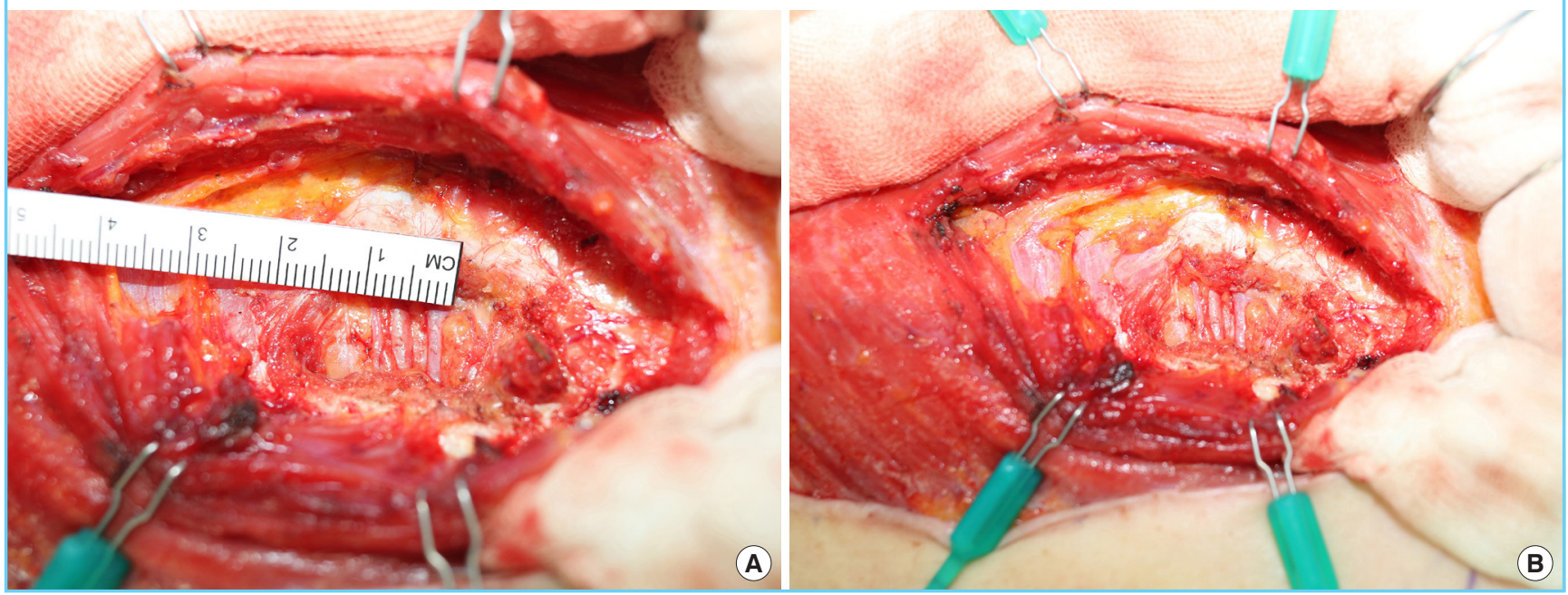
Table 1. Patient demographics and breast reconstruction types

\begin{tabular}{|lc|}
\hline Characteristic & Value \\
\hline No. of patients & 36 \\
No. of breasts/flaps & 38 \\
Age at the time of surgery (yr) & \\
$\quad$ Mean \pm SD & $47.7 \pm 6.0$ \\
Range & $32-59$ \\
BMI (kg/m²) & \\
Mean \pm SD & $24.6 \pm 4.6$ \\
Range & $18.6-37.9$ \\
Immediate reconstruction & 26 \\
$\quad$ Mastectomy weight, mean \pm SD (g) & $477.8 \pm 235.5$ \\
Standard mastectomy & 3 \\
Nipple-sparing mastectomy & 11 \\
Skin-sparing mastectomy & 12 \\
Delayed reconstruction & 12 \\
Harvest flap weight, mean \pm SD (g) & $749.1 \pm 306.9$ \\
Inset flap weight, mean \pm SD (g) & $474.8 \pm 149.6$ \\
Inset rate, mean \pm SD (\%) & $64.9 \pm 15.4$ \\
ICS used for recipient vessels, No. (\%) & \\
2nd ICS & $37 / 38(97.4)$ \\
3rd ICS & $1 / 38(2.6)$ \\
Total rib sparing, No. (\%) & $33 / 38(86.8)$ \\
Partial resection of the rib cartilage, No. (\%) & $3 / 38(7.9)$ \\
Total resection of the cartilage block, No. (\%) & $2 / 38(5.3)$ \\
\hline BMI, body mass index; ICS, intercostal spaces. & \\
\hline
\end{tabular}

al and venous anastomosis in all cases. Postoperatively, no emergent re-operations were performed, and all flaps survived without partial or total flap loss.

CT angiographic analysis revealed that the IMA $(2.26 \pm 0.32$ $\mathrm{mm}$ vs. $1.99 \pm 0.33 \mathrm{~mm}, \mathrm{P}=0.001)$ and $\mathrm{IMv}(2.52 \pm 0.46 \mathrm{~mm}$ vs. $2.05 \pm 0.42 \mathrm{~mm}, \mathrm{P}<0.001)$ had larger mean diameters at the second than at the third ICS (Table 2). The ICS was wider $(18.08 \pm 3.72 \mathrm{~mm}$ vs. $12.32 \pm 2.96 \mathrm{~mm}, \mathrm{P}<0.001)$ and the distance from the medial sternal border to the medial IMv was longer $(9.49 \mathrm{~mm}$ vs. $7.18 \mathrm{~mm}, \mathrm{P}<0.001)$ at the second ICS than at the third. Bifurcations of the IMv were found in $18.4 \%$ of cases at the second ICS and in $63.2 \%$ at the third ICS. The mean diameter of the DIEA was $2.42 \pm 0.27 \mathrm{~mm}$, while the mean diameter of the DIEV was $2.91 \pm 0.30 \mathrm{~mm}$. This diameter was measured at $1 \mathrm{~cm}$ above the DIEA origin. These vessels were larger than the IMVs at the second and third ICS. The discrepancy in diameter between donor and recipient vessels was smaller at the second than the third ICS (Table 2).

The diameters of the donor and recipient vessels were measured intraoperatively and were compared with CT measurements. The measurement difference was calculated by subtracting the $\mathrm{CT}$ measurement from the intraoperative measurement. In the intraoperative measurements, the mean diameter of the IMA in the second ICS was $2.64 \mathrm{~mm}$ (mean difference from CT measurement, $0.44 \mathrm{~mm}$ ), and the mean diameter of the DIEA
Table 2. Comparison of vascular anatomy in the second and third intercostal spaces in CT angiographic analysis $(n=38)$

\begin{tabular}{|c|c|c|c|}
\hline Variable & $\begin{array}{l}\text { 2nd ICS } \\
(\mathrm{mm})\end{array}$ & $\begin{array}{c}\text { 3rd ICS } \\
(\mathrm{mm})\end{array}$ & P-value ${ }^{a)}$ \\
\hline Width of ICS & $18.08 \pm 3.72$ & $12.32 \pm 2.96$ & $<0.001$ \\
\hline Diameter of IMA & $2.26 \pm 0.32$ & $1.99 \pm 0.33$ & 0.001 \\
\hline Diameter of DIEA & \multicolumn{2}{|c|}{$2.42 \pm 0.27$} & \\
\hline $\begin{array}{l}\text { Mean absolute differences of the } \\
\text { artery diameters }\end{array}$ & $0.37 \pm 0.32$ & $0.52 \pm 0.38$ & 0.002 \\
\hline Diameter of IMv & $2.52 \pm 0.46$ & $2.05 \pm 0.42$ & $<0.001$ \\
\hline Diameter of DIEV & \multicolumn{2}{|c|}{$2.91 \pm 0.30$} & \\
\hline $\begin{array}{l}\text { Mean absolute differences of the } \\
\text { vein diameters }\end{array}$ & $0.62 \pm 0.42$ & $0.89 \pm 0.51$ & $<0.001$ \\
\hline $\begin{array}{l}\text { Distance from medial sternal border } \\
\text { to medial vessel }\end{array}$ & $9.49 \pm 2.28$ & $7.18 \pm 2.13$ & $<0.001$ \\
\hline Existence of IMv bifurcation & $7(18.4)$ & $24(63.2)$ & $<0.001$ \\
\hline
\end{tabular}

Values are presented as mean $\pm \mathrm{SD}$ or number (\%). The computed tomography (CT) measurement was performed on the surgical side (38 breasts in 36 patients). ICS, intercostal spaces; IMA, internal mammary artery; DIEA, deep inferior epigastric artery; IMv, internal mammary vein; DIEV, deep inferior epigastric vein.

alp-values were calculated using independent t-test and chi-square test.

Table 3. Comparison of CT measurements and intraoperative measurements

\begin{tabular}{|lcccc|}
\hline Variable & $\begin{array}{c}\text { CT } \\
\text { measurement } \\
(\mathbf{m m})\end{array}$ & $\begin{array}{c}\text { Intraoperative } \\
\text { measurement } \\
(\mathbf{m m})\end{array}$ & $\begin{array}{c}\text { Differences } \\
(\mathbf{m m})\end{array}$ & $\begin{array}{c}\text { Absolute } \\
\text { difference } \\
(\mathbf{m m})\end{array}$ \\
\hline IMA & $2.19 \pm 0.29$ & $2.64 \pm 0.25$ & $0.44 \pm 0.40$ & $0.56 \pm 0.20$ \\
IMv & $2.14 \pm 0.27$ & $2.38 \pm 0.47$ & $0.24 \pm 0.56$ & $0.48 \pm 0.35$ \\
DIEA & $2.42 \pm 0.22$ & $2.41 \pm 0.32$ & $-0.01 \pm 0.45$ & $0.39 \pm 0.20$ \\
DIEV & $2.93 \pm 0.39$ & $2.43 \pm 0.40$ & $-0.49 \pm 0.59$ & $0.62 \pm 0.45$ \\
\hline
\end{tabular}

Values are presented as mean \pm SD. Difference was calculated by subtracting the computed tomography (CT) measurement from the intraoperative measurement.

IMA, internal mammary artery; IMv, internal mammary vein; DIEA, deep inferior epigastric artery; DIEV, deep inferior epigastric vein.

was $2.41 \mathrm{~mm}$ (mean difference from CT measurement, -0.01 $\mathrm{mm}$ ). The mean diameter of the IMv in the second ICS was 2.38 $\mathrm{mm}$ (mean difference from CT measurement, $0.24 \mathrm{~mm}$ ), and the mean diameter of the DIEV was $2.43 \mathrm{~mm}$ (mean difference from CT measurement, $-0.49 \mathrm{~mm}$ ) (Table 3). However, as the mean difference was simply the average of the calculated differences, the values had the potential of canceling out and appearing misleadingly small. Therefore, the means and standard deviations of the absolute values were also calculated to better represent the actual differences between measurements.

The diameters of the IMVs were also compared between the right and left sides. At the second ICS, the mean diameter of the right IMA was $2.25 \mathrm{~mm}$, and the mean diameter of the left IMA was $2.22 \mathrm{~mm}(\mathrm{P}=0.407)$. The mean diameters of the right and left IMvs were $2.61 \mathrm{~mm}$ and $2.32 \mathrm{~mm}$, respectively $(\mathrm{P}=0.038)$. Thus, IMv diameter was larger on the right side (Table 4). 
Table 4. Comparison of computed tomography measurement values of both IMA and IMv diameter in second ICS

\begin{tabular}{|lccc|}
\hline Diameter & Right $(\boldsymbol{n}=\mathbf{2 3})$ & Left $(\boldsymbol{n}=\mathbf{1 5})$ & P-value $^{\text {a) }}$ \\
\hline IMA (mm) & $2.25 \pm 0.16$ & $2.22 \pm 0.11$ & 0.407 \\
IMv (mm) & $2.61 \pm 0.25$ & $2.32 \pm 0.14$ & 0.038 \\
\hline
\end{tabular}

Values are presented as mean \pm SD.

IMA, internal mammary artery; IMv, internal mammary vein; ICS, intercostal spaces.

alp-values were calculated using independent t-test and chi-square test.

\section{DISCUSSION}

In this study, anatomical analysis was used to determine that the second ICS had more preferable anatomical features for microanastomosis for DIEP flap breast reconstruction. The second ICS was used for recipient IMVs in 37 of the 38 cases, while the third ICS was used in a single case in which an inframammary incision had been used for nipple-sparing mastectomy. A total rib-sparing technique was possible in more than $80 \%$ of cases, and no microvascular complication developed in any of the 38 consecutive cases. Both the IMA and the IMv were larger in diameter at the second ICS than at the third ICS. The IMv at the third ICS was significantly smaller than at the second because it exhibited bifurcation in more than half of the cases (64.9\%), while only $18.9 \%$ of cases displayed bifurcation at the second ICS. These anatomical features resulted in larger diameter discrepancies between the IMVs and the donor vessels of the DIEP flap at the third ICS than at the second ICS. At the second ICS, the ICS width was greater, and the distance from the medial sternal border to the medial IMv was longer. These characteristics allow vascular anastomosis to be performed more comfortably without rib resection.

Anatomical studies have reported that as the ICS number increases, the diameter of the blood vessels decreases, and bifurcation usually occurs at the fourth ICS. Arnez et al. [7] examined the IMVs at the third, fourth, and fifth ICS in fresh human cadavers. Of four potential patterns of venous anatomy, the most frequently observed was the extension of the IMv parallel with and medial to the IMA until the fourth ICS, at which point the IMv split into lateral and medial branches. The mean diameters of the IMv at the third, fourth, and fifth ICS were $2.8 \mathrm{~mm}, 2.6$ $\mathrm{mm}$, and $2.55 \mathrm{~mm}$, respectively, while the analogous measurements of the IMA were $2.8 \mathrm{~mm}, 2.6 \mathrm{~mm}$, and $2.6 \mathrm{~mm}$, respectively. In another analysis of cadavers by Clark et al. [8], by the third rib, $90 \%$ of the left IMvs and $40 \%$ of the right IMvs were observed to bifurcate; additionally, most of the examined IMvs had decreased in diameter to $2 \mathrm{~mm}$ or smaller by the fourth rib. Kim et al. [6] conducted a preoperative CT angiographic evalu- ation of IMVs at the second, third, and fourth ICS. At each, they measured the diameter of the IMA as well as the width and depth of the ICS for planning of DIEP flap breast reconstruction. Tuinder et al. [9] reported that the diameters of both the IMA and the IMv were $18 \%$ larger at the second ICS than at the third ICS [9]. However, no previous studies have compared the relative diameters of IMVs and pedicle vessels of the DIEP flap. In this study, we measured the diameters of both IMVs and DIEP pedicle vessels, and we found that the second ICS had a smaller discrepancy than the third in the diameters of the IMVs and the DIEP pedicle vessels.

In free flap surgery, a difference in diameter is often present between recipient vessels and flap vessels. According to a previous study, in 150 cases of microanastomosis, $33 \%$ of the artery and $50 \%$ of the vein anastomoses displayed vessel diameter discrepancy, which was defined as a graft-to-recipient diameter ratio greater than 1.5:1 or less than 1:1.5 [10]. It has been experimentally demonstrated that the patency of the anastomosis decreases as the diameter size discrepancy increases $[11,12]$. It can thus be concluded that a 1:1 ratio of graft-to-recipient diameter is ideal; barring this, a ratio of at least $0.75: 1$ should be ensured to attain satisfactory patency rates [12]. In this study, the diameter discrepancy of the IMv was 0.70:1 at the third ICS and $0.87: 1$ at the second ICS. The diameter discrepancy of the IMA was 0.82:1 at the third ICS and 0.93:1 at the second. Although different techniques can be used to overcome vessel diameter differences, microanastomosis of vessels with small diameter discrepancies can be performed more comfortably and is associated with a lower probability of technical error.

In their use of a rib-sparing approach, Sacks and Chang [13] initially accessed the IMVs via the third ICS, but they began using the second ICS due to its greater width and corresponding ease of access to the IMVs. However, skin-sparing mastectomy followed by immediate reconstruction may result in a skin opening of limited size, making the third ICS preferable to the second with regard to the performance of microvascular anastomosis. In this study, we used the second ICS as the recipient site in 37 of the 38 cases, and all patients survived without partial or total flap loss. The authors used a skin hook retractor connected to a rubber band to retract the skin flap, and the second ICS could be accessed in all cases (Fig. 2). In cases of nipple-sparing mastectomy, when the skin flap was not effectively retracted and it was difficult to access the second ICS, a 1- to 2-cm lateral extension of the lateral radial incision facilitated exposure of the second ICS.

Differences in vessel size between the right and left ICS have been reported. Tan et al. [14] reported that the right IMA tended to be larger than the left. On average, in that study, the right 
side measured $2.25 \mathrm{~cm}$ and the left side measured $2.05 \mathrm{~cm}$ [14]. We similarly found the diameter of the right IMv to be statistically significantly larger than that of the left $(2.61 \mathrm{~mm}$ vs. 2.32 $\mathrm{mm}$, respectively; $\mathrm{P}=0.038$ ). In contrast, we found that the diameter of the IMA was not statistically significantly different between the right and left sides $(2.25 \mathrm{~mm}$ vs. $2.22 \mathrm{~mm}$, respectively; $\mathrm{P}=0.407$ )

Total rib-sparing procedures were performed in $86.8 \%$ of all cases in this study, while partial or block resection of rib cartilages was performed in five cases. In those five cases, the mean ICS width was smaller $(13.2 \mathrm{~mm}$ vs. $18.08 \mathrm{~mm})$ and the mean body mass index (BMI) was higher $\left(24.82 \mathrm{~kg} / \mathrm{m}^{2}\right.$ vs. $\left.24.35 \mathrm{~kg} / \mathrm{m}^{2}\right)$ than the mean values of the study population. In our experience, total rib sparing is possible when the ICS has a width of $14 \mathrm{~mm}$ or greater. In patients with relatively high BMIs, however, the second ICS tends to be deeply situated, making it difficult to access the IMVs.

It is of note that a single surgeon with less than 3 years of experience in microsurgical breast reconstruction performed all of the surgical procedures. However, no microvascular complications occurred in any of the 38 consecutive cases. This suggests that the IMVs of the second ICS are reliable recipient vessels even for inexperienced surgeons. Microvascular anastomosis can be performed more comfortably at the second than at the third ICS given that the IMVs have larger diameters that are similar to those of the DIEA and DIEV, the ICS is wider, and the distance from the sternal border to the IMVs is greater. Similar to our findings, a recent study reported that the second ICS was wider and the diameter of the IMv prior to bifurcation was larger, so use of the second ICS was recommended [15].

The revision rate of DIEP flaps is $3.38 \%$. Venous insufficiency is the most common cause of revision, with a reported frequency of $86.7 \%$ [16]. When the recipient vein is significantly smaller than the donor vein, postoperative venous thrombosis can result. In our study, $64.9 \%$ of the IMVs in the third ICS were bifurcated, and the mean IMv diameter at the third ICS was significantly smaller than at the second. Even with vein couplers, it is known that the smaller the diameter, the greater the complications, such as venous insufficiency and fat necrosis [17].

Although the use of the second ICS has many anatomical advantages, it also carries disadvantages. The second ICS is located deeper or more upwardly slanted than the third, and exposure via a limited mastectomy incision can be difficult. Additionally, a longer pedicle is necessary, especially in low-set breasts. Therefore, selection of the level of the ICS in DIEP flap breast reconstruction must be individualized with consideration of various factors. Given that the optimal ICS could not be predicted using patient characteristics such as BMI and height, preoperative CT angiographic evaluation of both recipient and donor vessels can be an effective way to choose the ICS for recipient vessels $[6,18]$.

This study had several limitations. First, the sample size was relatively small; however, we were still able to identify a significant difference in the anatomical features of the second and third ICS. Second, there may have been errors in the measurement of vessel diameter using CT angiography. Since the course of the DIEA and DIEV near the origin are not straight, measurements of their diameter on CT images can be inaccurate. Similarly, CT angiography can be influenced by the density of the contrast medium, the size of the display field, and the wall thickness $[19,20]$. However, the purpose of this study was to identify relative differences in vascular diameter among the IMVs at the second ICS, the IMVs at the third ICS, and the pedicle vessels of the DIEP flap. Although differences could exist between the CT measurements and the actual diameters of the vessels, the uniformity of CT measurement allowed us to compare the relative diameters of the IMVs of the second and third ICS and the DIEP pedicle vessels.

The IMVs at the second ICS were found to have more favorable anatomic features for recipient vessels in DIEP flap breast reconstruction than those of the third ICS. Compared to the third ICS, the second ICS is wider, has a longer distance from the medial sternal border to the medial IMv, and has a lower likelihood of IMv bifurcation. Furthermore, the diameter of the $\mathrm{IMv}$ in the second ICS is similar to that of the DIEV.

\section{NOTES}

\section{Conflict of interest}

No potential conflict of interest relevant to this article was reported.

\section{Ethical approval}

The study was approved by the Institutional Review Board of Ewha Womans University Mokdong Hospital (IRB No. 202004-013) and performed in accordance with the principles of the Declaration of Helsinki. Written informed consents were obtained.

\section{Patient consent}

The patients provided written informed consent for the publication and the use of their images.

\section{Author contribution}

Conceptualization: KJ Woo. Data curation: IH Seong, KJ Woo. Formal analysis: IH Seong, KJ Woo. Methodology: KJ Woo. Project administration: KJ Woo. Writing - original draft: IH 
Seong. Writing - review \& editing: all authors.

\section{ORCID}

Ik Hyun Seong

https://orcid.org/0000-0003-0289-0222

Kyong-Je Woo

\section{REFERENCES}

1. Panchal H, Matros E. Current trends in postmastectomy breast reconstruction. Plast Reconstr Surg 2017;140:7S$13 S$.

2. Vollbach FH, Heitmann CD, Fansa H. An appraisal of internal mammary artery perforators as recipient vessels in microvascular breast reconstruction: an analysis of 515 consecutive cases. Plast Reconstr Surg Glob Open 2016;4:e1144.

3. Haywood RM, Raurell A, Perks AG, et al. Autologous free tissue breast reconstruction using the internal mammary perforators as recipient vessels. Br J Plast Surg 2003;56:68991.

4. Majumder S, Batchelor AG. Internal mammary vessels as recipients for free TRAM breast reconstruction: aesthetic and functional considerations. Br J Plast Surg 1999;52:286-9.

5. Follmar KE, Prucz RB, Manahan MA, et al. Internal mammary intercostal perforators instead of the true internal mammary vessels as the recipient vessels for breast reconstruction. Plast Reconstr Surg 2011;127:34-40.

6. Kim H, Lim SY, Pyon JK, et al. Preoperative computed tomographic angiography of both donor and recipient sites for microsurgical breast reconstruction. Plast Reconstr Surg 2012;130:11e-20e.

7. Arnez ZM, Valdatta L, Tyler MP, et al. Anatomy of the internal mammary veins and their use in free TRAM flap breast reconstruction. Br J Plast Surg 1995;48:540-5.

8. Clark CP 3rd, Rohrich RJ, Copit S, et al. An anatomic study of the internal mammary veins: clinical implications for freetissue-transfer breast reconstruction. Plast Reconstr Surg 1997;99:400-4.

9. Tuinder S, Dikmans R, Schipper RJ, et al. Anatomical evaluation of the internal mammary vessels based on magnetic resonance imaging (MRI). J Plast Reconstr Aesthet Surg 2012;65:1363-7.

10. Cakir B, Akan M, Akoz T. The management of size discrepancies in microvascular anastomoses. Acta Orthop Traumatol Turc 2003;37:379-85.

11. Monsivais JJ. Microvascular grafts: effect of diameter discrepancy on patency rates. Microsurgery 1990;11:285-7.

12. Harris JR, Seikaly H, Calhoun K, et al. Effect of diameter of microvascular interposition vein grafts on vessel patency and free flap survival in the rat model. J Otolaryngol 1999; 28:152-7.

13. Sacks JM, Chang DW. Rib-sparing internal mammary vessel harvest for microvascular breast reconstruction in 100 consecutive cases. Plast Reconstr Surg 2009;123:1403-7.

14. Tan O, Yuce I, Aydin OE, et al. A radioanatomic study of the internal mammary artery and its perforators using multidetector computed tomography angiography. Microsurgery 2014;34:277-82.

15. Sasaki Y, Madada-Nyakauru RN, Samaras S, et al. The ideal intercostal space for internal mammary vessel exposure during total rib-sparing microvascular breast reconstruction: a critical evaluation. J Plast Reconstr Aesthet Surg 2019;72: 1000-6.

16. Vanschoonbeek A, Fabre G, Nanhekhan L, et al. Outcome after urgent microvascular revision of free DIEP, SIEA and SGAP flaps for autologous breast reconstruction. J Plast Reconstr Aesthet Surg 2016;69:1598-608.

17. Broer PN, Weichman KE, Tanna N, et al. Venous coupler size in autologous breast reconstruction: does it matter? Microsurgery 2013;33:514-8.

18. Khoo A, Rosich-Medina A, Woodham A, et al. The relationship between the intercostal distance, patient height and outcome in microsurgical breast reconstruction using the second interspace rib-sparing internal mammary vessel exposure. Microsurgery 2014;34:448-53.

19. Suzuki S, Furui S, Kaminaga T. Accuracy of automated CT angiography measurement of vascular diameter in phantoms: effect of size of display field of view, density of contrast medium, and wall thickness. AJR Am J Roentgenol 2005; 184:1940-4.

20. Woo KJ, Park JW, Mun GH. The lateral calcaneal artery as an alternative recipient vessel option for heel and lateral foot reconstruction. Microsurgery 2018;38:164-71. 